\title{
The Experiences of Receiving Education in Motivational Interviewing-A Qualitative Study among Dental Health Professionals
}

\author{
Åsa Larsson ${ }^{1}$, Jennie Furuhall ${ }^{2}$, Sebastian Malmqvist ${ }^{3}$, Michelle Lau ${ }^{3}$, Jonas Erdenborg ${ }^{3}$ and Annsofi Johannsen ${ }^{3, *}$ \\ ${ }^{1}$ Public Dental Health Service, Department of Pediatric, Eastman institute, Stockholm County Council, Sweden \\ ${ }^{2}$ Public Dental Health Service, Uppsala County Council, Sweden \\ ${ }^{3}$ Department of Dental Medicine, Karolinska Institutet, Huddinge, Sweden
}

*Corresponding author: Annsofi Johannsen, Associate Professor, Division of Oral Diseases, Department of Dental Medicine, Karolinska Institutet, Huddinge, Sweden, Tel: +46739807369; E-mail: Annsofi.Johannsen@ki.se

Received: 18 Dec, 2020 | Accepted: 30 Dec, 2020 | Published: 05 Jan, 2021

Citation: Larsson A, Furuhall J, Malmqvist S, Lau M, Erdenborg J, et al. (2020) The Experiences of Receiving Education in Motivational Interviewing-A Qualitative Study among Dental Health Professionals. Int J Dent Oral Health 6(6): dx.doi.org/10.16966/2378-7090.349

Copyright: (C2020 Larsson A, et al. This is an open-access article distributed under the terms of the Creative Commons Attribution License, which permits unrestricted use, distribution, and reproduction in any medium, provided the original author and source are credited.

\begin{abstract}
Aim: The purpose was to explore dental hygienists and dentists' experiences of receiving education in motivational interviewing and thereby improving their ability to achieve behavioral changes in patients.

Materials and Methods: A qualitative study design was chosen, four dental hygienists and five dentists from two Public Dental Health Service clinics in Stockholm county, Sweden participated in the study. Open-ended questions which focused on experiences of motivational interviewing, thus exploring the advantages and disadvantages of using motivational interviewing, and how the participants perceived the patient's experience. The interviews were transcribed, and a coding process was used according to qualitative conventional content analysis.

Results: A core category was identified as "Education in motivational interviewing led to perceived improvement in behavioral change interventions". Subsequently three categories were determined; "Education and awareness of motivational interviewing" Implementation of motivational interviewing" and "Factors that may influence the use of motivational interviewing". The dental hygienists and dentists reported that they found the education in motivational interviewing very useful and they had improved their communication skills. They also become aware that it is difficult, and requires a complex set of skills to implement. Time and need of practical training were the main obstacles to using it, while they perceived that when they used motivational interviewing, they got the patients more involved in their treatment.

Conclusions: The present study showed that motivational interviewing education and practical training improved the communication skills of dental care givers as well as increased the patients' compliance and involvement. Time restrictions, difficulty to use motivational interviewing and sometimes patient's resistance were cited as barriers.
\end{abstract}

Keywords: Behavior change intervention; Dental education; Motivational interviewing; Oral health

\section{Introduction}

People's health, both general and oral health is to a large extent dependent upon different behaviors. Trying to change an unhealthy behavior is therefore of utmost importance to achieve good health. The relationship between oral health and general health is important as oral health is considered an integral component of general health and quality of life could be worsened due to oral health problems [1].

Oral hygiene instructions are part of patient education and are keystone interventions during all stages of treatment to reach good oral health [2]. A large part of this education focus on how to change a behavior, e.g., towards better oral hygiene habits or smoking cessation [3]. By using behavioral intervention methods, an improvement of the individual's plaque control over time has been shown [4].

Motivational Interviewing (MI), developed during the 19801990s, is a collaborative counselling method used for strengthening a person's own motivation and commitment to change a behaviour, i.e., working with patients and activates their own motivation and resources thereby enabling them to change their behaviors $[5,6]$. MI has previously been shown, in systematic reviews, to be effective for improving health-related behaviors $[7,8]$.

The effect of MI has been evaluated in patients with periodontal diseases regarding oral hygiene and the results showed no significant difference regarding plaque and bleeding scores [9]. The use of MI in smoking cessation gave a modest but significant increase effect compared to short advice or regular care [10]. Jarvinen M, et al., [11] reported that behavioral interventions increased patient compliance, e.g., the effectiveness of self-care and the frequency of interdental cleaning. Similar results were reported by Werner H, et al., [12] where psychological interventions versus education/information regarding plaque index showed a small but statistically significant advantage for the intervention group. 
Studies have investigated the influence of education in MI within different areas performed by dental hygienists (DH) and dentists as well as students and the results have favored MI to be beneficial for the patients [13-15]. The study by Woelbre JP, et al., [15] showed that students with an 8-hours workshop regarding MI, significantly improved MI-compliant conversation compared to non-trained students when using Motivational Treatment Integrity Code (MITI-d) performed by a blinded psychologist. Using MI resulted in a significant improvement in the self-efficacy of interdental cleaning among the patients but no improvement in other aspects such as periodontal indices.

The effect of behavioral intervention e.g., MI as a communication tool has been thoroughly investigated, however, in order to implement and spread the MI skills it is also important to investigate the dental professional's knowledge and their experience of working with MI with the patients.

The purpose was to explore DHs' and dentists' experiences of receiving education in $\mathrm{MI}$ and thereby improving their ability to achieve behavioral changes in patients.

\section{Materials and Methods}

This study was approved, $758-31 / 3$, by the Ethics committee in Stockholm, Sweden, an oral and written informed consent from each participant before commencing the interview.

\section{Study group}

A qualitative design with interviews was used to capture the DHs and dentists views of MI. In 2017, interviews were conducted with four DHs and five dentists, at two Public Dental Health Service (PDHS) clinics in Stockholm county, Sweden who had received MI education and practical training at their clinics. Interviews were conducted with both DHs and dentists in order to investigate and compare their experiences. Participants with different genders, ethnic backgrounds and ages were selected.

\section{MI education}

A three-day education (in total 24 hours) including both theory of MI and practical exercises. The course leader was a certified MI practitioner and had extensive experience of leading the education in MI. The practical exercises consisted of role-playing with openended questions, to identify patient's ambivalence about change and exploring patients' ability to change.

\section{Interviews and procedure}

An interview guide with open-ended questions was formulated according to the literature about MI $[6,16]$. The questions focused on previous experiences of MI, experiences of an MI course in which treatment situations with MI was used, the advantages and disadvantages of using MI, support from the organization, and how the participants perceived the patient's experience of the MI approach.

The authors had no previous relations to the DHs or dentists, and conducted the interviews individually at a location chosen by the participant. The interviews were 35-45 min long. The participants were informed that their involvement would be anonymous and that the collected material would remain confidential. All interviews were recorded on tape between February-March 2017, and then transcribed.

Two of the authors ( $\AA \mathrm{L}, \mathrm{JF})$ conducted one interview each and then discussed with a senior researcher, (AJ, with previous experience in qualitative methodology), the thematic areas that should be included and explored more in the following interviews. Seven additional interviews were conducted. All interviews were discussed in succession among the authors to ensure high quality interpretations of interview data.

\section{Data Analysis}

The transcriptions were then read and codes were written in the text margins that briefly captured the essence of the content. After the first reading, the authors grouped the codes into preliminary subcategories independently, with focus on the study aim. Then the choice of codes was discussed until consensus was reached.

Coding was carried out according to qualitative conventional content analysis, which includes analysis of both the manifest and latent content and interpretation of the text material with depth and level of abstraction [17]. Visible, evident components identified manifest content, and latent content clarified the deeper underlying meaning of the text. In conventional content analysis the coding categories derives directly from the text data, which is a process of inductive category development.

\section{Results}

The nine participant's were between 30-63 years of age and number of years after graduation was 3 to 30 years. In the analysis, a core category was identified as "Education in MI led to perceived improvement in behavioral change interventions" and was built up from three categories "Education and awareness of MI", "Implementation of MI" and "Factors that may influence the use of MI (Table 1).

Category one "Education and awareness of MI" was divided into two subcategories, "earlier education of MI" and "present education of MI" (Table 2). Category two "implementation of MI" was divided into three sub categories, "in the treatment situation", "achieve with MI", and "patient-centered care" (Table 3). MI was used in the communication with the patients to promote prevention of oral diseases, the patients should take responsibility for their oral hygiene, and MI was shown to be patient-centered and perceived as positive from the patents. The third main category "Factors that may influence the use of MI" was divided into three sub-categories "the professions experience of MI, "the management perspective", "and pros and cons with MI" (Table 4).There was a positive attitude towards the use of MI but lack of time was the main obstacle to using it even if they received support from the organization.

\section{Education and awareness of MI}

Earlier education of MI: Five of the informants had previously

Table 1: Dental hygienists and dentists perception of the education in motivational interviewing.

\begin{tabular}{|l|l|l|}
\hline \multicolumn{1}{|c|}{ Theme } & \multicolumn{1}{|c|}{ Category } & \multicolumn{1}{c|}{ Sub-categories } \\
\hline & $\begin{array}{l}\text { Education and } \\
\text { awareness of } \mathrm{MI}\end{array}$ & $\begin{array}{l}\text { Earlier education of MI } \\
\text { MI education }\end{array}$ \\
\cline { 2 - 3 } $\begin{array}{l}\text { Education in MI } \\
\text { led to perceived } \\
\text { improvement } \\
\text { in behavioral } \\
\text { change } \\
\text { interventions }\end{array}$ & $\begin{array}{l}\text { Implementation } \\
\text { of MI }\end{array}$ & $\begin{array}{l}\text { In treatment situation } \\
\text { Achieve with MI } \\
\text { Patient-centered care }\end{array}$ \\
\cline { 2 - 3 } & $\begin{array}{l}\text { Factors that may } \\
\text { influence the use } \\
\text { of MI }\end{array}$ & $\begin{array}{l}\text { The professions experience of } \\
\text { MI } \\
\text { The management perspective } \\
\text { Pros and Cons with MI }\end{array}$ \\
\hline
\end{tabular}


received some training or attended education in MI. Four of the informants were completely unfamiliar with MI before they received the education at the PDS. (Table 2).

Present education of MI: All informants felt that the MI training they had received was good.The education included both theory and practical exercises, where they were able to practice on each other by asking open ended questions. Comments from the informants were that they previously had used open ended questions in the conversations with the patients without reflecting about it. Several informants felt that it was difficult to apply the training in the clinical practice due to repetitive nature of the method (Table 2).

\section{Implementation of MI}

In the treatment situation: A majority of informants stated that they used MI in each patient contact. Some responded that they used it mainly at examinations visits and some used MI in all treatments. It was also stated that when they meet a patient several times, it was easier to use open questions with an MI approach (Table 3).

Achieve with MI: Several informants mentioned that the patients felt satisfied and that it resulted in improved oral health in the patient. The informants also mentioned that is important to give the patient relevant information, make the patient feel safe and confirmed, and to win the patient's trust. The focus is to help the patient to find a solution to the problem, which also means that the patient has more control over the treatment (Table 3).

Patient-centered care: The answers from the informants differed on this question; some said that it is subconscious, that it is something you use spontaneously without thinking about it. Many informants believed that the patients felt more cared for and were more involved in their treatment. It emerged during the interviews that some patients misinterpreted MI and believed that the therapist had a lack of competence when asking some of the questions. Many informants actively listened, confirmed, summarized and reflected upon the patient statements. All informants stated that using open-ended questions is the most essential part of MI (Table 3).

\section{Factors that may influence the use of MI}

The Professions experience of MI: Many of the informants

Table 2: The informant's education of $\mathrm{Ml}$ with sub-categories and quotations.

\begin{tabular}{|l|l|}
\hline Education and awareness of MI \\
\hline Earlier \\
education of MI & $\begin{array}{l}\text { "It was probably during the education, although } \\
\text { they didn't call it MI, but there was a lot of focus on } \\
\text { asking the patient with open questions, not giving } \\
\text { information." } \\
\text { "It was here at work, where we took a course in MI. } \\
\text { There was nothing during the education." } \\
\text { "At the dental hygienist education, I do not } \\
\text { remember if it was the second or third year." }\end{array}$ \\
\hline MI education & $\begin{array}{l}\text { "I think it was very good. The education was very } \\
\text { clear and it has been beneficial that everyone has } \\
\text { completed the course." } \\
\text { "Partly good, partly not! The good thing was that } \\
\text { You got ideas and thoughts about how to perform } \\
\text { an MI dialogue. Some of the practical exercises were } \\
\text { repeated many times, otherwise it was good." } \\
\text { "The training was theoretically good but the first } \\
\text { part of the practical training was perhaps not suited } \\
\text { to our work." }\end{array}$ \\
\hline
\end{tabular}

Table 3: This category describes the informant's implementation of $\mathrm{MI}$, what they want to achieve with $\mathrm{Ml}$, with subcategories and quotations.

\begin{tabular}{|c|c|}
\hline \multicolumn{2}{|r|}{ Implementation of MI } \\
\hline $\begin{array}{l}\text { In the treatment } \\
\text { situation }\end{array}$ & $\begin{array}{l}\text { "In all treatment situations." } \\
\text { "During examinations, when we looked at } \\
\text { the x-rays and self-care habits, i.e., when } \\
\text { you meet the patient for the first time." } \\
\text { "Mostly when I have the examinations, then } \\
\text { I have the most time to talk. When You have } \\
\text { started the treatment it is more difficult." } \\
\text { "Almost always, if I'm not very late or stressed." }\end{array}$ \\
\hline Achieve with MI & $\begin{array}{l}\text { "Increased empowerment in the patient." } \\
\text { "That the patients feel safe and confirmed and I can } \\
\text { win the patient's trust." } \\
\text { "To change patients' behavior." }\end{array}$ \\
\hline $\begin{array}{l}\text { Patient-centered } \\
\text { care }\end{array}$ & $\begin{array}{l}\text { "I use it sub-consciously and I think most people } \\
\text { think it's good." } \\
\text { "Yes, I do, I work with open-ended questions." } \\
\text { "It is very clear when it becomes inconvenient but } \\
\text { otherwise, I think the patient has a positive attitude } \\
\text { to it." }\end{array}$ \\
\hline
\end{tabular}

Table 4: The third category describes factors that may influence the se of $\mathrm{Ml}$, the professions and management perspective, with subcategories and quotations.

\begin{tabular}{|c|c|}
\hline \multicolumn{2}{|r|}{ Factors that may influence the use of $\mathrm{MI}$} \\
\hline $\begin{array}{l}\text { The Professions } \\
\text { experience of } \mathrm{MI}\end{array}$ & $\begin{array}{l}\text { "It is good, but sometimes it is very difficult due to } \\
\text { time pressure." } \\
\text { "Mostly, the patients perceive that it was } \\
\text { motivating and also fun." } \\
\text { "The more I use it, the more natural it becomes } \\
\text { and then it becomes so obvious that you wonder } \\
\text { why you haven't done it before." }\end{array}$ \\
\hline $\begin{array}{l}\text { The management } \\
\text { perspective }\end{array}$ & $\begin{array}{l}\text { "Good and less good. Sometimes it feels like they } \\
\text { want to expose you." } \\
\text { "They support those who need support and they } \\
\text { encourage those who use MI, so it's rather clear." } \\
\text { "It would have been good with follow-up of the MI } \\
\text { education and training." }\end{array}$ \\
\hline $\begin{array}{l}\text { Pros and cons } \\
\text { with } \mathrm{MI}\end{array}$ & $\begin{array}{l}\text { "The patients feel more involved in their own oral } \\
\text { health and what can happen." } \\
\text { "You get a more involved patient and you can use } \\
\text { MI with patients of different ages and in various } \\
\text { treatment situations." } \\
\text { "One advantage is that if you use MI you can avoid } \\
\text { conflicts with the patients, meaning that they } \\
\text { come up with their own solutions, which makes it } \\
\text { easier to succeed." } \\
\text { "It is difficult to implement MI because You have } \\
\text { not enough time set aside for the patients." } \\
\text { "In order to be successful in using MI it is } \\
\text { important to undergo continues training." }\end{array}$ \\
\hline
\end{tabular}


stated that it was difficult to work with MI. It can sometimes feel uncomfortable when, for example, reflecting upon what the patient had said. The informants also felt that it was difficult to implement MI due to lack of time. However, most respondents felt that when patients reflected on themselves, they had got an understanding of their oral health.

The management perspective: Several informants stated that they were often encouraged to work with MI but that it also could be felt as a constraint. The management had set a clear goal for communication to take place in an MI-based approach. Some participants felt monitored and stated that they received more reminders, to use the method, than other colleagues at the clinic.

Pros and cons with MI: The informants stated that, by using MI, patients became more satisfied and felt cared for. By using MI in the right way, some informants perceived that potential conflicts could be avoided by allowing the patient to come up with solutions and that it was easier to get compliance from the patient. The majority of the informants stated that there was not sufficient time to perform MI with each patient and that it was difficult to learn and required a lot of practice.

\section{Discussion}

The study showed that the informants were overall satisfied with the education and the practical training which had improved their communications skills. They also wanted to continue working with MI and they perceived that the patients were more often satisfied and felt cared for when using this approach. This is in agreement with Woelbre JP, et al. [15] who showed that education improved MI skills. Moreover, Faustino-Silva DD, et al., [18] showed that eight-hour MI training for dental staff was sufficient to increase MI competence compared to a control group who didn't get any training. The two-year follow-up also showed that they used and acted in the spirit and techniques of MI compared to the control group. This was in line with our study, where the majority of the informants perceived that the MI education was useful even if they were aware of some hindrances. The majority of the informants felt that lack of time was the main hindrance to working with MI. Apart from that, the DHs and dentists perceived that the education was very useful and that it had made them aware of that they earlier had used open questions in the conversation with the patients, however not in a structured way.

In order to succeed in using behavioral change interventions, it has earlier been stated that it is of utmost importance that the dental staff have knowledge of health behavior theory and effective behavior change methods and are well-educated and trained in person-centered health communication [19]. Another important issue is the setting or environment in which the communication should take place to be effective. Inglehart $\mathrm{MR}$, et al. highlighted in that matter that dental offices are indeed an excellent setting for communication about lifelong oral health behavioral change [20].

Several informants felt that it was difficult to apply the MI training in their clinical work, which may indicate that it is difficult to use the method and more training as well as follow-up sessions are required. Studies have reported that developing skills in MI is complex, takes time and requires continuous training [13,21]. In the present study the DHs and dentists reported that it took time to learn MI and that a lot of training is needed. They also stated that it is important to get support from the management to be able to practice MI. In a qualitative study, among DHs, it was reported that MI training had improved their communication skills and that they had implemented MI into their routines in ways they felt were effective, feasible and sustainable in spite of barriers [13].
The current study also revealed that there was a difference between the informants and the extent to which they used MI. One explanation for that could be that are differences between the professions. DHs focus on health promotion including change of behaviors e.g., dietand oral hygiene habits and tobacco cessation compared to the dentists who work with restorative treatments. MI training is integrated in the dental hygiene curriculum with a combination of didactic/pedagogical and individual feedback from the teachers [14,22-24].

MI has been used in periodontal treatment in order to enhance the outcome of non-surgical therapy, however, studies have shown conflicting results $[4,25]$. Despite, that the studies couldn't show any clear relationship, MI has shown to be associated with higher selfefficacy beliefs in maintaining a good level of oral hygiene among patients treated for periodontitis. This was also in agreement with the results from the present study, that using MI increased the patient's empowerment to change their behavior and they were more involved in the treatment and satisfied.

\section{Strength and limitation of the study}

When using a qualitative design, it is important to raise aspects such as, dependability which was achieved by the interviews being structured and the use of an interview guide [17]. All informants got the same questions, but not necessarily in the same order, and any follow-up questions were dependent upon the responses, to provide further depth and detail to the answers.

Strength of the study was that the participants consisted of people with different ages, gender and number of working years. The nine informants who participated in the study came from two clinics from the Stockholm region in Sweden. This is a limitation of the study; it would have been interesting if more clinics had received the same education, in order to increase the transferability of the study.

The interviewers had no relationship with the informants. The interviewer's had received training and had experience of asking open-ended questions and the interviews were also discussed with the senior author.

Confirmability is another aspect to consider in qualitative studies. To confirm that it is important to describe each step of the data analysis. The descriptions were given with presentations of the study findings, e.g., by presenting several quotations from the interviewees. In the present study, three authors performed their own preliminary analyses of the data which were then revised after discussions with the other authors until a consensus was reached, which increased the confirmability. The results of this study could be transferred and implemented at other dental organizations that are interested in increasing the competence of MI among their dental staff.

\section{Conclusions}

The present study showed that MI education and practical training improved the communication skills of dental care givers as well as increased the patients' compliance and involvement. Time restrictions, difficulty to use MI and sometimes patient's resistance were cited as barriers.

\section{Conflicts of Interest}

The authors declare no conflicts of interest.

\section{Acknowledgement}

This study was supported by Karolinska Institutet, Sweden. 


\section{References}

1. Gift HC, Atchison KA (1995) Oral health, health, and health-related quality of life. Med Care 33: 57-77.

2. Tonetti MS, Eickholz P, Loos BG, Papapanou P, van der Velden U, et al. (2015) Principles in prevention of periodontal diseases: Consensus report of group 1 of the 11th European Workshop on Periodontology on effective prevention of periodontal and peri-implant diseases. J Clin Periodontol 42: 5-11.

3. Sanz M, Meyle J (2010) Scope, competences, learning outcomes and methods of periodontal education within the undergraduate dental curriculum: A consensus report of the 1st European Workshop on Periodontal Education-position paper 2 and consensus view 2. Eur J Dent Educ14: 25-33.

4. Kopp SL, Ramseier CA, Ratka-Kruger P, Woelber JP (2017) Motivational interviewing as an adjunct to periodontal therapy-a systematic review. Front Psychol 28: 279.

5. Rollnick S, Miller WR (1995) What is motivational interviewing? Behav Cogn Psychother 23: 325-334.

6. Miller WR, Rollnick S (2002) Motivational interviewing: preparing people for change. $2^{\text {nd }}$ Edition, Guilford Publications, New York, USA.

7. Burke BL, Arkowitz H, Mechola M (2003) The efficacy of motivation interviewing: a meta-analysis of controlled clinical trials. J Consult Clin Psychol 71: 843-861.

8. Kay EJ, Vascott D, Hocking A, Nield H (2016) Motivational interviewing in general dental practice: A review of the evidence. Br Dent J 221: 785-791.

9. Carra MC, Detzen L, Kitzmann J, Woelber JP, Ramseier CA, et al. (2020) Promoting behavioural changes to improve oral hygiene in patients with periodontal diseases: A systematic review. J Clin Periodontol 47: 72-89.

10. Lindson-Hawley N, Thompson TP, Begh R (2015) Motivational interviewing for smoking cessation. Cochrane Database Syst Rev 7: CD006936.

11. Jarvinen $M$, Stolt M, Honkala E, Leino-Kilpi H, Pöllänen M (2018) Behavioural interventions that have the potential to improve selfcare in adults with periodontitis: A systematic review. Acta Odontol Scand 76: 612-620.

12. Werner $H$, Hakeberg $M$, Dahlström L, Eriksson $M$, Sjögren $P$, et al. (2016) Psychological Interventions for Poor Oral Health: A Systematic Review. J Dent Res 95: 506-514.

13. Curry-Chiu ME, Catley D, Voelker MA, Bray KK (2015) Dental Hygienists' Experiences with Motivational Interviewing: A Qualitative Study. J Dent Educ 79: 897-906.
14. Mills A, Kerschbaum WE, Richards PS, Czarnecki GA, Kinney JS, et al. (2017) Dental Hygiene Students' Perceptions of Importance and Confidence in Applying Motivational Interviewing During Patient Care. J Dent Hyg 91: 15-23.

15. Woelber JP, Spann-Aloge N, Hanna G, Fabry G, Frick K, et al. (2016) Training of Dental Professionals in Motivational Interviewing can Heighten Interdental Cleaning Self-Efficacy in Periodontal Patients. Front Psychol 7: 254

1. Miller WR, Rollnick S (2012) Motivational Interviewing: Helping People Change. $3^{\text {rd }}$ Edition, Guilford Publications, New York, USA.

16. Graneheim UH, Lindgren BM, Lundman B (2017) Methodological challenges in qualitative content analysis: A discussion paper. Nurse Educ Today 56: 29-34.

17. Faustino-Silva DD, Meyer E, Hugo FN, Hilgert JB (2019) Effectiveness of Motivational Interviewing Training for Primary Care Dentists and Dental Health Technicians: Results from a Community Clinical Trial. J Dent Educ 83: 585-594.

18. Jönsson $\mathrm{B}, \mathrm{Abrahamsson} \mathrm{KH}$ (2020) Overcoming behavioral obstacles to prevent periodontal disease: Behavioral change techniques and self-performed periodontal infection control. Periodontol 84: 134144.

19. Inglehart MR (2019) Motivational Communication in Dental Practices: Prevention and Management of Caries over the Life Course. Dent Clin North Am 63: 607-620.

20. Schwalbe CS, Oh HY, Zweben A (2014) Sustaining motivational interviewing: a meta-analysis of training studies. Addiction 109: 1287-1294.

21. Bray KK, Catley D, Voelker MA, Liston R, Williams KB (2013) Motivational interviewing in dental hygiene education: curriculum modification and evaluation. J Dent Educ 77: 1662-1669.

22. Johannsen A, Bolander-Laksov K, Bjurshammar N, Nordgren B, Fridén C, et al. (2012) Enhancing Meaningful learning and Selfefficacy through collaboration between Dental hygienist and Physiotherapist students-a Scholarship project. Int J Dent Hyg 10: 270-276.

23. Johansson AC, Johannsen G, Uhlin K, Johannsen A (2014) Dental hygienist students' learning about motivational interviewing. Dent J 2: 65-77.

24. Stenman J, Wennstrom JL, Abrahamsson KH (2018) A brief motivational interviewing as an adjunct to periodontal therapy-A potential tool to reduce relapse in oral hygiene behaviours. A threeyear study. Int J Dent Hyg 16: 298-304. 